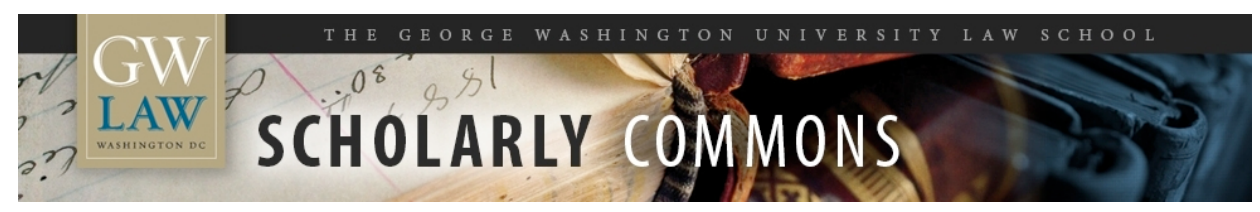

\title{
Prize and Reward Alternatives to Intellectual Property
}

Michael B. Abramowicz

George Washington University Law School, abramowicz@law.gwu.edu

Follow this and additional works at: https://scholarship.law.gwu.edu/faculty_publications

Part of the Law Commons

\section{Recommended Citation}

Abramowicz, Michael B., Prize and Reward Alternatives to Intellectual Property (2019). Prize and Reward Alternatives to Intellectual Property, in Research Handbook on the Economics of Intellectual Property Law (P.S. Menell \& B. Depoorter eds., forthcoming 2019). ; GWU Law School Public Law Research Paper No. 2019-13; GWU Legal Studies Research Paper No. 2019-13. Available at SSRN: https://ssrn.com/ abstract $=3366608$

This Chapter is brought to you for free and open access by the Faculty Scholarship at Scholarly Commons. It has been accepted for inclusion in GW Law Faculty Publications \& Other Works by an authorized administrator of Scholarly Commons. For more information, please contact spagel@law.gwu.edu. 


\title{
Prize and Reward Alternatives to Intellectual Property
}

\author{
Michael Abramowicz*
}

\section{Contents}

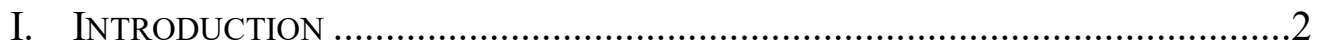

II. HISTORY AND SEMINAL SCHOLARSHIP ................................................4

III. AdMINISTRATIVE DESIGN ISSUES .................................................. 8

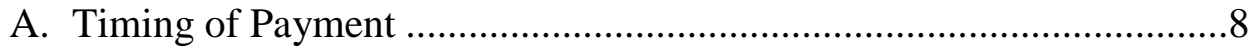

B. Cash vs. Other Incentives ............................................................... 9

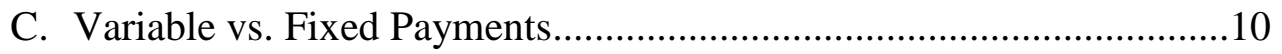

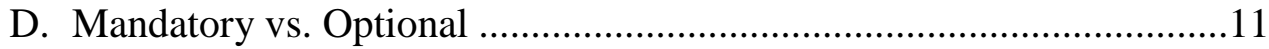

E. General vs. Targeted ..........................................................................11

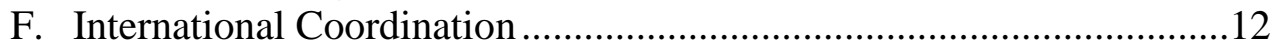

IV. VALUATION OF INVENTIONS AND WORKS................................................ 13

A. Measurement Based on Use ...............................................................14

B. Market Mechanisms ...........................................................................15

C. Flexible Ex Post Valuation and Hybrid Mechanisms ...........................17

V. COMPARISON With TRAditional Intellectual Property Systems AND

OTHER ALTERNATIVES ..........................................................................18

A. Effects on Innovation .....................................................................19

B. Effects on Redundant Innovation...................................................22

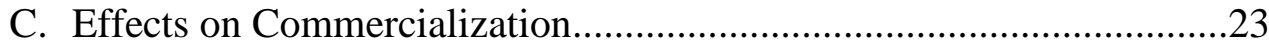

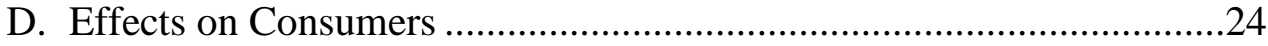

\footnotetext{
* Professor of Law, George Washington University.
} 


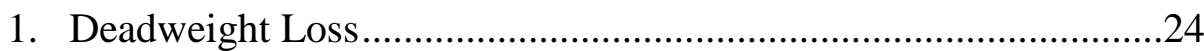

2. Distribution and Labor Incentives ...........................................25

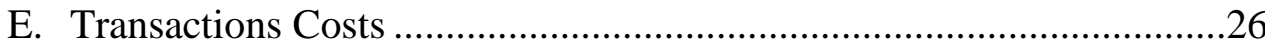

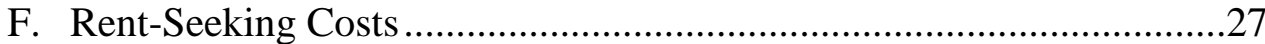

G. Other Policy Options...............................................................22

1. Grants ................................................................................27

2. Governmental Purchases and Tax Credits ..................................28

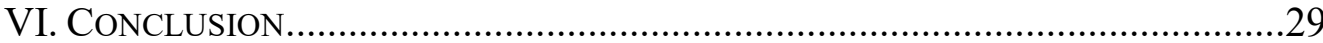

\section{INTRODUCTION}

This chapter surveys the literature on alternatives to intellectual property, focusing especially on alternatives to patent law, but with some attention as well to copyright. It does not consider the question whether intellectual property rights are justified, but assumes that absent some form of governmental innovation, inventions and works of authorship might be underproduced relative to the social optimum. The chapter thus considers how institutions besides traditional property rights compare relative to one another and to traditional intellectual property systems. The chapter considers only briefly the possibility that government itself might produce inventions and works of authorship or that government might indirectly produce these by funding research. A considerable literature already exists on governmental peer review and research administration, and so these mechanisms are considered only insofar as they compare to the institutions that are the primary focus of this chapter, prize and reward systems.

A prize or reward system is one in which the government gives an award to a person or entity that has produced an invention or work deemed socially valuable, based on an assessment of the contribution of that invention or work. The chapter will use the word "prize" to describe systems that give an award only to a single contributor or small group of contributors, based for example on who has given the best contribution in a designated area or who is first to have solved a particular problem. A "reward system," by contrast, will be used to refer to a system in which funds are available for a large number of contributors, to be distributed based on assessments of the quality of their contributions. As Burstein \& Murray (2015) note, much of the academic focus has been on reward systems, but prizes have enjoyed more recent policy prominence.

As the prize-reward distinction suggests, there are many ways in which prize and reward systems can be structured. The form of the award may vary, consisting usually of cash but sometimes of other governmental benefits. In some proposals, the total award is a fixed amount, but in others, the total award may vary 
depending on the assessed quality of the contributions. An award system may be an optional alternative to an intellectual property system, or could be instituted as an exclusive alternative. A system may cover a wide range of possible inventions or works, or it may target a particular type of invention or work, such as pharmaceuticals or songs.

Perhaps most importantly, prize and reward systems may differ in the mechanisms used to assess the quality of the contributions. One approach is for the government to observe market behavior in an effort to estimate the demand for a new invention or work and the improvement in social welfare produced by its release into the public domain. Such observation might be conducted by an administrative agency or through judicial proceedings, for example in a takings suit. Some commentators have sought to identify the specific formulas that government should use in conducting valuation, while others have argued that the government should have substantial freedom to take into account a wide range of considerations in making assessments of contributions. Meanwhile, other contributors have argued that to restrict dangers associated with governmental discretion, a market mechanism should be used to assess contributions.

The effectiveness of the valuation mechanism is critical to an assessment of how alternatives to intellectual property compare to traditional intellectual property systems. If the government miscalibrates awards, then these awards can lead to production of inventions and works that add little to social welfare and may thus produce lower value than alternative uses of governmental funds, including tax reductions. On the other hand, if the government can accurately measure social welfare, then a prize or reward system may contribute substantially to social value. If social benefits of an invention or work are a substantial multiple of the cost of incentivizing its production, then the social benefits of a prize or reward program may be positive. A full accounting, however, must account for any reduction in social welfare attributable to the need to raise sufficient tax revenue to accomplish the program.

In the real world, of course, neither a prize or reward system nor a system of intellectual property rights will perfectly calibrate incentives and lead private parties to undertake all investments in the creation of inventions and works that have a positive social return. A critical virtue of intellectual property systems is that they minimize governmental discretion in assessing the value of works. But the need to determine when to grant intellectual property rights and to adjudicate the propriety of and infringement of such rights dictates a considerable governmental role. Thus, the effectiveness of a patent office and the courts are critical to assessing how existing intellectual property systems compare to prize or reward systems. To the extent that intellectual property systems do constrain administrative and judicial discretion with rules, the question becomes to what extent the rules successfully align creator incentives with social welfare. 
In principle, the ultimate comparison of prize systems with intellectual property systems is an empirical one. This chapter will provide some historical context, but there is little empirical data, particularly on the prize or reward system side of the ledger. And even to the extent some experimentation with prize or reward systems has occurred, the heterogeneity of such systems counsels restraint in attributing the virtues or vices of any one such system to all of them. Of course, it is also important not to compare some hypothetical ideal prize or reward system against a functioning intellectual property system. After all, there are many competing proposals to improve patent and copyright law, and even if there were broad scholarly agreement about the design of an ideal system, political considerations may make suboptimal intellectual property inevitable — and would likely mean the same for a prize or reward system.

This review thus does not seek to determine whether intellectual property systems should be abandoned in favor of prize or reward systems or whether the latter should be introduced as a complement to the latter. Rather, it is to provide an overview of the theoretical terrain, to identify the potential weaknesses of prize or reward systems and to point out analogous imperfections in our existing intellectual property system. The chapter will highlight some considerations, such as incentives to commercialize inventions or works, transactions and administrative costs, and rent-seeking costs, which are sometimes omitted from the intellectual property calculus, but must be taken into account in a full comparison of intellectual property to prize or reward systems.

The chapter proceeds as follows. Part II will provide an overview of the history and early scholarship on prize and reward systems, including nineteenth century antecedents and contemporary prizes and proposals. Part III considers administrative design issues, other than valuation. This includes questions such as the choice between prizes and rewards, whether awards should be general or targeted, and how international coordination of prize or reward systems could work. Part IV then turns to valuation mechanisms, considering traditional administrative and judicial mechanisms, as well as market mechanisms. Finally, Part V compares prize-or-reward systems to the existing intellectual property system.

\section{HISTORY AND SEMINAL SCHOLARSHIP}

Governmental prizes at one time represented a significant component of governmental innovation policy and appeared to be a serious competitor to traditional intellectual property systems. As documented by Burrell and Kelly (2014), Parliament gave numerous invention awards from 1732 to 1840 based on its institutional assessment of the contribution of inventions. Parliament was also in the business of granting patent term extensions on an ad hoc basis and thus used its discretion in both types of systems. Burrell and Kelly argue that the shift from prizes to patents changed not so much because of a perception that intellectual 
property systems were inherently superior to prize systems, but because Parliament's "role began to shift from that of a grand tribunal for the nation to something more like that of a dedicated legislature." (p. 885) Parliament's failure, however, to vest prize discretion in some other administrative institution, along with the failure of other countries to create prize systems on the scale of England's, suggests the existence of some distrust of prize systems.

In the heyday of prizes, Parliament did not always reserve to itself the right to adjudicate prizes, but instead often resorted to administrative determinations. This was true of what is undoubtedly the most famous invention prize in history, the prize for a method for precise determination of longitude at sea. The Board of Longitude gave awards for two rival approaches to the problem, one involving a method of lunar distance calculation, and the other depending on accurate timekeeping. Howse (1998). Navigators could identify high noon local time, so if a timepiece informed them of the time at the port of origin, they could extrapolate the extent of a ship's progress around the globe. A modern debate relevant to prize systems generally is whether the Board was excessively stingy with John Harrison, who invented a timepiece allegedly capable of functioning on water, perhaps because he was a carpenter rather than a member of the scientific establishment. Sobel (1995) intimates that the Board failed to discharge its duty properly, though Siegel (2009) argues that the Board's reluctance to grant a full award to Harrison resulted from Harrison's inability to provide a method of replicating his timepieces. Siegel argues, "Even in the relatively simple case wherein the legislature sought to promote a solution to a single, specific problem, and in which a single, discrete product embodied the sought-after innovation, Parliament could not usefully specify the test that would determine whether the invention had won the prize in a way that would eliminate the need for administrative discretion." (p. 61) The tale can thus be seen as a cautionary one about governmental abuse of discretion or as one highlighting the difficulty of constructing ex ante rules and the advantages of flexibility inherent in prize systems.

Prizes had a less central role in England in the second half of the $19^{\text {th }}$ century, but prizes were still given in some sectors. Brunt et al. (2012) analyze annual competitions held by the Royal Agricultural Society from 1839-1939, including 1,986 awards from 15,032 entries. (p. 658) It is difficult to use econometrics to assess the incentive effects of prizes, for the same reason that it difficult to assess the incentive effects of intellectual property; ordinarily, there is no control group. Brunt et al., however, exploit a system by which the areas in which prizes were offered rotated from here to year over a 15 year period, and they find that the availability of prizes in a particular increased inventions in the relevant art. Because the prize system was a complement to the patent system, the increase in invention was manifested by an increase in patenting activity in the area covered by the prize system in the time around the show. Similarly, Moser and Nicholas 
(2013) analyze the effects of prizes at the Crystal Palace Exhibition in 1851. They show that technologies that won prizes were more likely to receive patents than technologies that did not win a prize. This may demonstrate that there were positive reputational benefits from receiving prizes beyond the money offered or that judges were skilled at identifying patentable inventions. Moser and Nicholas argue for the former interpretation.

Prizes also existed in other countries. Indeed, a number of countries had offered a longitude prize before the prize that Harrison claimed. Nicholas (2013) documents an extensive system of prizes in $19^{\text {th }}$ century Japan. Adopting an approach similar to that of Brunt et al., Nicholas exploits variation in the size of prizes over time to estimate the degree to which prizes affected innovation. He finds a significant effect when measuring innovation based on patenting activity. Prizes were granted in individual prefectures rather than nationally, and Nicholas argues that "within the host prefecture the cost of the prize contests was high relative to the value of patent capital they created." (p. 596) Adjoining prefectures enjoyed significant knowledge spillovers from these competitions. Nicholas's historical account highlights a potential problem with prize proposals that we will consider below: that a jurisdiction that sponsors a prize may not be able to appropriate a high percentage of the benefits from invention. This problem is, of course, particularly acute in the modern world as a result of international information flows.

Intellectual property systems gradually began to dominate prize systems throughout the world in the nineteenth century. Perhaps this occurred in part because patent systems were constructed in a general way so that any inventor meeting the specified criteria could benefit from them, while prizes were given sporadically and in an ad hoc manner. Some commentators, however, urged the prizes be given in lieu of monopoly rights granted by patents. R.A. Macfie (1883, p. vi), for example, argued, "In every patent there should be a condition that the State, from public moneys, or moneys supplied by individuals, shall be entitled to demand that the value of the invention be estimated, and, on this value being paid (with a liberal percentage added in consideration of 'compulsory sale'), the use of the invention should become free to all the Queen's subjects (even in the Colonies, so far as privileges granted there do not clash)." Macfie collects early commentary on prize systems, including a proposal by Sir John Sinclair that recognized the international dimension of the problem and proposed an agreement among the European powers and the United States to reward inventors, as well as a proposal by Sir David Brewster for creating a Board of "scientific and practical" men to administer a prize system. (pp. 33-34)

By the twentieth century, prizes largely faded in the public consciousness as a method for encouraging invention, but there were occasional proposals to revive them. For example, Polanvyi (1944) adopted a theme similar to Macfie's, highlighting the costs of monopoly. He argued that "[i]n order that inventions may 
be used freely by all, we must relieve inventors of the necessity of earning their rewards commercially and must grant them instead the right to be rewarded from the public purse." (p. 65) Polanvyi envisioned not eliminating the patent system, but grafting onto it a system of compulsory licenses. Meanwhile, the modern economic literature on prizes dates to Wright (1983), who compares the costs and benefits of patents, prizes, and research grants. Wright formalizes Macfie's and Polanvyi's concerns about monopolization, showing that prizes can improve efficiency by eliminating the deadweight loss associated with pricing of patented products and services above marginal cost. He also addresses a number of other issues that we will explore below, such as the danger of excessive research into particular inventions.

The law and economics of prizes began to receive sustained academic attention in literature beginning in the 1990s. There was also a concomitant increase in the use of prizes as a mechanism for encouraging innovation. Prior to that, there were some instances in which governments encouraged research through prizes. For example, the United States Atomic Energy Act of 1946, Pub. L. No. 79-585, 60 Stat. 755 (codified as amended at 42 U.S.C. $\$ \$ 2011-2297 \mathrm{~g}$ ), created a board to give rewards for military energy innovations, but there are few other examples. In recent years, the Defense Advanced Research Projects Agency (DARPA) has offered numerous prizes. (Schotchmer 2004, p. 2). Other governmental prizes include the Department of Defense Wearable Power Prize, the Department of Energy Grand Challenges, and the NASA Centennial Challenges. Stine (2009). Congress required the National Science Foundation to create a program to fund innovation inducement prizes. Science, State, Justice, Commerce, and Related Agencies Appropriations Act, Pub. L. No. 109-108 (109th Cong. 2006). Meanwhile, Senator Bernie Sanders proposed replacing the patent system for pharmaceuticals with a reward system. Medical Innovation Prize Fund act, S. 1137, 112th Cong. (2011). The lack of any other apparent support in Congress highlights, however, that while prize systems have received support as accessories to the patent system in discrete areas, there appears to be little chance of instituting a comprehensive reward system, especially one that would displace the patent system, in the near future.

There has also been increased private interest in prizes, particularly for philanthropic purposes. For example, the Virgin Earth Challenge offers a $\$ 25$ million prize for inventions that might combat global warning by anthropogenic greenhouse gases. (Adler 2011). The Ansari X-Prize has offered \$10 million for the development of reusable manned aircraft, and numerous other prizes exist as well. (McKinsey \& Co. 2009) Murray et al. (2012, p. 1791) argue that the various private prizes "blend a myriad of complex goals, including attention, education, awareness, credibility and demonstrating the viability of alternatives." Burstein \& Murray (2015) offer a detailed study of one such prize, the Progressive Insurance 
Automotive X Prize, explaining how it achieves innovation goals that help to overcome information asymmetries and significant uncertainty. Because prizes are still relatively rare, they may generate more publicity than other means of privately funding innovation, such as research grants. Adler (2011, p. 16) notes that this has sometimes led to investments much larger in total than the value of the prize. This also may help explain the relative popularity of prize systems compared to reward systems. A caution is that if benefits are attributable to publicity, any successes attributable to prizes might not scale if a prize or reward system were increased to near the size of the patent system. Burstein \& Murray (2015) argue that prize systems may not scale as well as the patent system or other reward systems.

\section{ADMINISTRATIVE DESIGN ISSUES}

\section{A. Timing of Payment}

Both prize and reward systems generally make awards after the relevant research, inventions, or work are complete, in contrast to research grants, which are generally given ex ante based on specification of research to be conducted. Because awards are granted ex post, inventors or creators must raise funds necessary to conduct the research or create the work. Bakker (2013, p. 1811) argues that before 1750 , the time lag made prizes a relatively ineffective method of inducing inventive activity. With capital markets, however, prizes in theory should be capable of encouraging activity to be performed before awards will be made. Venture capitalists or banks thus serve a role in assessing research plans under a prize system, and a cost of the system is that they must be compensated for their labor and the risk that they undertake. This may also make it difficult to offer exceptionally large prizes; Kalil (2006, p. 7) speculates that a prize system might not be able to induce sufficient private investment in a new particle accelerator for theoretical physics research. Brennan et al. $(2012$, p. 4) argue that an assessment of who can best bear risk is essential to evaluation of a prize system, stating that "prizes are likely to be better when the needs can be specified, necessary or preferred technological solutions are not known, and the procuring party needs to share the risk by guaranteeing a minimum return to the first successful innovator."

The payment of prizes and rewards after research is complete still leaves a number of decisions concerning the payout approach. The payout can occur as soon as research is complete, though Abramowicz (2003) argues that payments should be delayed to provide better information to decisionmakers about the contribution of inventions. Especially if the intellectual property system is retained and a prize or reward system is an option, this can reduce the danger of an adverse selection problem in which only those inventors with "lemons" agree to forego their intellectual property rights in exchange for a prize or reward. Love and Hubbard (2007, pp. 1539-40) suggest that payouts be made over time, with subsequent 
payments changing based on observation of markets. Similarly, Williams (2012, p. 772) urges that some payment be made based on adherence to technical requirements, but additional payments should be based on whether an invention achieves sufficient market acceptance.

\section{B. Cash vs. Other Incentives}

Virtually all proposals assume that the benefits to be granted by the government will come in the form of cash. Galle (2014, p. 881) notes, however, that some cash prizes may "reduce positive contributions from inframarginal producers by crowding out their internal motivation" and thus noncash prizes may sometimes be superior. Prizes can also provide financial benefits without directly providing cash. Ridley et al. (2006) suggest that a prize might be the right to obtain expedited review of another drug. This proposal was adopted into law, with respect to specified diseases, by the Food and Drug Administration Amendments Act of 2007, § 1102, codified at 21 U.S.C. $\$ 360 n$, which created a system of priority review vouchers. Similarly, Fisher and Syed (2012, p. 16) note the possibility that pharmaceutical companies might be rewarded for creating a medication for poor consumers by having patent life extended on some other drug. Of course, the government would need to exercise discretion in determining how much patent life to grant. Wright (1983) notes that the fact that the government does not generally tailor patent terms to inventions suggests a concern that government may not exercise its discretion well, a concern that might affect both cash and other prizes.

Another alternative to cash prizes is for the government to purchase innovative products and services for itself or to help consumers with such purchases. Lichtman (1997) argues that the government might be able to reduce deadweight loss more cheaply by giving coupons for pharmaceuticals to the poorest consumers than by buying out the patent. His model assumes linear demand and that the government knows the most each consumer is willing to pay for a product. If the government gives coupons to just one-quarter of customers, in magnitudes just large enough to bring them up to the top of the bottom quartile, then the pharmaceutical patent owner's incentive will be to lower the price so that it can get gain sales from these customers, as well as from the next quartile of consumers. Of course, Lichtman recognizes that the government will not have perfect information, but he argues that if the government can spend just 1 in 8 dollars correctly, this approach may be more effective dollar-for-dollar than a patent buyout. Lichtman also notes that the government may have tax data and other data enabling the government to make fine-grained assessments of consumer valuations.

If, however, the government gives coupons to some consumers who would not need them, then that would not merely undermine the government's plan by leading to unnecessary spending, but would also reduce the pharmaceutical patent owner's incentive to lower prices to capture the consumers with coupons. 
Abramowicz (2003) offers a simulation model varying the quality of the government's estimates of demand. With sufficiently good governmental information, coupons will be cheaper per dollar of deadweight loss removed than patent buyouts. But below some point, patent buyouts are likely to be more expensive. This simulation still assumes linear demand, however. Fisher and Syed (2012, p. 21) argue that this assumption is unrealistic in the context of drugs in the developing world, because the vast majority of consumers are able to pay very little in comparison to consumers in the developed world. One could argue that their poverty gives these consumers low valuations of the drugs, however, and that the deadweight loss from their exclusion from the market is low. Fisher and Syed's argument depends on the proposition that willingness to pay is not a valid basis for assessing social welfare and that alternative means of achieving redistribution are not viable.

\section{Variable vs. Fixed Payments}

Concerns about governmental exercise of discretion are also central to the decision of whether to grant a fixed prize or a variable reward. Clancy and Moschini (2013) offer a model showing that ideally the government would offer rewards equal to the social innovation value. With a guaranteed prize at a certain level, the system cannot take advantage of private researchers' information about the expected value of inventions that they might create; Wright (1983, p. 704) notes that the absence of such information creates an informational advantage of patents over prizes. A guaranteed prize may also be problematic if the winner of a contest may opt for some other form of compensation, such as the patent or copyright system, instead of the contest. Ding \& Wolfsetetter (2011) note that if a prize is set too low, only those with low contributions that would not fare well on the market will submit their work for the prize.

Another approach, initially suggested by Abramowicz (2003), is to have a fixed "pot" to be distributed among an unknown number of contributions in proportion to assessments of the value of the contributions. Hollis and Pogge (2008) elaborate how this might be used in the context of pharmaceuticals. Love and Hubbard (2007, p. 1536) argue that a benefit of this approach is that it provides a government assurance of how much it will have to pay. A fixed pot reduces the risk, cited by Wright (1983, p. 703), that with a variable prize, the government may lowball its evaluation in the hope of spending money. As Wright recognizes, however, if a reward system is repeated over time, the government will have at least some reputational incentives not to renege on its commitments. Another disadvantage of both the fixed pot and the fixed single prize relative to variable prizes is that these mechanisms do not tend to move the system toward the point where the marginal benefit of prizes equals the marginal cost. If the government can be trusted to value inventions based on social welfare, then the system should 
equilibrate at this point without further governmental invention to increase the size of the prize pool.

\section{Mandatory vs. Optional}

Whether payments are fixed or variable, a critical question is whether participation in the system is optional, in which case participants may choose whether to seek traditional intellectual property rights instead, or mandatory. Shavell and van Ypersele (2001) note that adverse selection is a potential drawback of an optional system. They assume that an inventor knows the demand for an invention created, but the government does not, so the only inventors to choose a prize will be those who expect to be overcompensated relative to the patent system. To the extent that the patent system's valuations are correlated with social value, this creates a lemons problem. To combat this problem, the government can offer a reward corresponding to the lowest possible demand for the inventor's product, based on the government's calculations. Alternatively, the government might offer higher rewards, thus inducing greater participation (and greater reduction of deadweight loss) but at some cost of unnecessary payments.

Love and Hubbard (2007) defend a mandatory system, particularly in the pharmaceuticals context. A mandatory system eliminates the transactions costs associated with patents and guarantees to researchers and entrepreneurs that they need not clear rights to existing technology. A disadvantage of a mandatory system is that it makes it more difficult to experiment and transition, though a mandatory system might be introduced for some relatively small class of inventions. An additional disadvantage is that if the government pays too little, there will be no alternative system for encouraging innovation. With an optional system, low governmental payments may reduce social welfare but only by reducing the benefits associated with the prize system; the traditional intellectual property system can continue to function.

\section{E. General vs. Targeted}

In principle, proposals that target pharmaceuticals could be broadened to cover any form of intellectual property. Indeed, commentators often argue that intellectual property works relatively well in the context of pharmaceuticals in contrast to other areas of patent law, because patent scope can be relatively clearly defined, so the focus on pharmaceuticals may seem inappropriate. Kremer and Williams (2010), however, argue that an alternative to the intellectual property system might be tried in specific sectors before it is generalized, and Fisher and Syed (2012) argue that there are some factors that make pharmaceuticals a particularly appropriate area for experimentation. They note that "government agencies regularly collect and assess data concerning the incidence and impact of 
diseases and thus are well positioned to ascertain the welfare gains that could be reaped by developing and distributing vaccines or treatments for each ailment." (p. 3)

The advantage of a more general system is that it may be able to stimulate precisely those innovations that are underfunded by the patent system. Abramowicz (2003) notes that with a fixed pot, inventors are most likely to opt in if they believe that the inventions that they will produce will have high measured social welfare relative to the private gains that could be appropriated through a patent. This could reflect a form of adverse selection, but only if there are reasons to believe that the social welfare calculations will be systematically inaccurate. Fisher and Syed likewise argue that targeting a fund toward specific diseases, rather than to pharmaceuticals in general might be a mistake, because a more general prize fund will tend to stimulate work on inventions that are expected to have large impacts on welfare that cannot easily be monetized by the patent system.

\section{F. International Coordination}

International harmonization has reduced the ability of countries to free-ride on the intellectual property system, though at the cost of greatly reduced access to inventions, particularly pharmaceutical inventions, in the developed world. If individual countries gave prizes or rewards to inventors or creators of works in an uncoordinated way, then there would be incentives to free-ride. Duffy (2004a, p. 54) notes that each government "has incentives to behave strategically in contributing toward the reward." A government might not give prizes or rewards but still reap the benefits of innovations generated from prizes or rewards. A partial response for this is to grant prizes or rewards solely based on contribution to the jurisdiction providing the prizes or rewards. Calandrillo (1998, p. 354) suggests offering awards based on use and utility as observed in the jurisdiction providing awards. If, for example, the United States alone offered prizes, innovators would still be able to exploit their intellectual property in other countries. This would have the benefit of reducing free-riding, but of course would mean continued difficulty in the developed world accessing patented inventions.

If, however, countries can choose whether to offer intellectual property or rewards, then there may be a strategic incentive to offer rewards but then to undervalue the rewards. In principle, a system of harmonization could seek to ensure that countries (or perhaps, only developed countries) offer rewards offer them at a sufficiently high level and also that countries do not discriminate against foreign inventors and creators in paying rewards. Meanwhile, if some countries offered rewards while others offered intellectual property, this could mean that inventors would face increased transactions costs, reducing some of the benefits that have been achieved from international cooperate among patent offices. These 
issues would be reduced if inventors and creators could opt into a prize or reward system but still retain their intellectual property rights.

In theory, it might be possible to create a system of international coordination and harmonization for prize and reward systems. It also might be possible that the developed countries would agree to underwrite an international prize fund to benefit the developing world, as suggested by Stiglitz (2006). But any such initiatives could require a long time and a great deal of diplomatic effort. Under current law, it is not clear whether it is even permissible for a country to abandon intellectual property for a reward system. Fisher and Syed (2012, p. 34) argue that a mandatory system would violate the TRIPS agreement, article 27 of which requires that "patents shall be available for any inventions ... in all fields of technology." Article 30, however, permits "limited exceptions [that] do not unreasonably conflict with a normal exploitation of the patent and do not unreasonably prejudice the legitimate interests of the patent owner." Perhaps the alternative revenue provided by a prize or reward system would lead to a conclusion that such a system would not prejudice rights holders' interests.

\section{VALUATION OF INVENTIONS AND WORKS}

By far the most important practical problem in design of a reward system is the challenge of valuing contributions. (A prize system avoids this problem to some extent by setting fixed prizes in advance, though that means that the government must at least be able to determine how much to offer for particular types of inventions.) As Roin (2014, p. 1035) notes, "Social value is notoriously difficult to measure objectively in most circumstances, and measuring the social value of innovations - which are unique goods by definition-may be particularly difficult." While we will explicitly compare prize and reward systems to traditional intellectual property in Part $\mathrm{V}$, the question whether a particular prize or reward system would track social value better than traditional intellectual property looms large in the calculation.

As a preliminary matter, one must have a handle on what counts as the social value that a prize-or-reward system should be awarding. Several points are worth making. First, the baseline target is the gross social surplus from invention. One should not subtract the inventor's direct costs or the cost of risk facing the inventor. The assumption underlying both traditional intellectual property and a prize-orreward system is that private incentives will align with social ones if creators expect to receive the gross social surplus, because they will invest until the marginal increase in expected gross social surplus increases the marginal cost of investment. To be sure, what ultimately matters is the net surplus, but we will assume that if the inventor receives an award equivalent to gross surplus, the inventor will have incentives to optimize net surplus. Consistent with this observation, existing 
intellectual property systems do not concern themselves with how much the inventor has invested.

Second, a payment to a creator should ideally net out the value of any independent rents that the creator receives for the creation. Suppose, for example, that by inventing a new flying car, an inventor would receive substantial first-mover advantages, aided by the trademark system. If a reward system is used as an alternative to a patent system, then the ideal reward would be equal to the social benefits of the flying car minus the rents the inventor receives naturally or with the help of trademark law. A reward system that paid the full social value of an invention and also allowed inventors to appropriate value for it in other ways would be overcompensating inventors, leading to investments past the point at which the marginal social benefits justified the cost.

Third, and more subtly, the payment should also net out gross social surplus that would have been achieved absent the invention without the incentive of the reward system but will not be achieved as a result of the invention. This can be relevant when an inventor's diligence leads to a discovery shortly before it would have been made in the absence of a patent or reward system. Because invention is cumulative, sometimes Invention A makes it possible to invent Invention B. If Invention B would have been invented soon even if no patent or reward incentive existed, then the only increase in social welfare that should be attributable to Invention B should be any acceleration in invention that occurred as a result of the reward system. The analogous point in the patent context is that the nonobvious doctrine should depend on whether an invention was induced by the patent system. See Graham v. John Deere Co., 383 U.S. 1, 11 (1966); Abramowicz and Duffy (2011).

\section{A. Measurement Based on Use}

Perhaps the most obvious approach to assessing the social value of an invention is to measure use of the product by consumers. This might be accomplished either by forcing some consumers to pay for the product or to consider purchases by consumers of the product once it is placed in the public domain. Guell and Fischbaum (1995, p. 225), who propose patent buyouts for pharmaceutical products, suggest that the pharmaceutical be sold initially in a test market. Shavell and van Ypersele (2001) suggest that the government wait until the product is placed in the public domain and the government observes the goods sold.

This approach runs into at least three significant difficulties. First, there is not an identity between a patented invention and a consumer product. Abramowicz (2003, p. 143). (There often is an identity, however, between a copyrighted work and a consumer product, so this approach may be easier to implement in the copyright context.) Often, many innovations are inputs into a single product, and an innovation may be an input into many different products. Hopenhayn et al. 
(2006, p. 1047). A further complication, identified by Chari et al. (2012), is that producers may have an incentive to manipulate market signals about the value of their inventions, for example by bribing other producers. Chari et al. conclude that the relative strength of patents and reward system depends on how costly it is for producers to manipulate market signals.

Second, measurement can be difficult even when there is an identity between product and contribution. One problem, identified by Coase (1946) and applied to the patent reward context by Duffy (2004a), is that buyouts can cause misallocations of resources even where a good is used. For example, government transportation may lead consumers to live inefficiently far from a city. The fact that consumers take advantage of the transport does not mean that they value it at the cost of the production. The relevant question is how much consumers "would have demanded the good if government policy were different and they had expected to pay the full cost of the product." (p. 43). Duffy points out that we should like to know the most that consumers would pay for a product, but "the government will have no data to answer that question because consumers are not paying full costs and never expected to do so." (Duffy, p. 43). Meanwhile, manipulation by producers can cause distortions. Roin (2014, p. 1037 n.174, pp. 1059-60) observes that producers may sell goods below marginal cost to inflate apparent demand, not only thwarting value measurement but also leading to inefficient overuse.

Third, even measurement of use may face administrative complications. For a pharmaceutical, whose use is probably considerably easier to measure than many other inventions', we would need to be able to determine total manufacturing by generic firms, perhaps not an insurmountable problem but one requiring some degree of coordination. Sometimes, once use is known, it may be possible to estimate consumer value, subject to the objections above, but often, the government may take shortcuts, such as assuming benefits based on clinical trials. Hollis and Pogge (2008, pp. 30-31) point out that this approach may be flawed, because clinical trials may feature the consumers most likely to benefit from an invention.

\section{B. Market Mechanisms}

An alternative approach, or perhaps sometimes a complementary one, is to use a market mechanism to estimate the value of intellectual property forfeited by its owner in exchange for a buyout price. Of course, such a system can function only as an adjunct to the existing intellectual property system. The mechanism in the literature that has received the most attention is offered by Kremer (1998), who suggests allowing an optional system in which an inventor can submit an invention for an auction to the public. With some small probability, the auction is consummated; the rest of the time, the invention is placed in the public domain. (p. 1147) The virtue of this system is that the government can harness private 
information. The government pays the patent owner an amount based on the bids when the auction is not consummated.

The system, however, invites a number of objections. A patentee might make side payments to bidders. Collusion can even include implicitly; a company might bid often on another company's intellectual property in the hope of reciprocation. Kremer suggests combating this by paying some multiple of the third-highest bid. (p. 1158) The effectiveness of this solution depends on the number of plausible bidders. More generally, an auction might not be competitive, especially for exceptionally valuable intellectual property. It may not be worthwhile to undertake the expense of researching the value of intellectual property if there is only a small probability that the sale will be consummated. Clancy \& Moschini (2013, p. 229) notes also that potential bidders must have sufficient information to make meaningful evaluations. In addition, truly random assignment will lead to some patents being kept in private hands. "The government must be willing to allow the cure for AIDS to remain in private hands if random chance would have it." (Duffy 2004a, p. 48)

A more complex problem that Kremer addresses is that different patents may be substitutes or complements. If two patents are complements, rewards may be too high if they are auctioned separately; given the high probability each of two perfect complements will be assigned to the public domain, the other will command nearly the full value of both together. Meanwhile, the value of one patent will be greatly lowered if a substitute patent will likely be placed in the public domain. Kremer responds by suggesting joint randomization, i.e. that all close complements and substitutes be auctioned simultaneously, with all either randomized to the public domain or to private ownership, though not necessarily by the same owners. This may, however, not always be administratively feasible, if different inventions are produced at different times.

An alternative market mechanism, still subject to concerns about substitutes and complements but avoiding some of the other difficulties, is suggested in a footnote by Duffy (2004a, p. 47 n.37). Under this mechanism, the government announces an intention to take some intellectual property owned by a publicly traded firm, but it does not announce the precise time at which this taking will occur. At some moment, trading is suspended and the government announces that it has taken the property, but that the takings amount will be paid to the shareholders of record at the moment of the taking. Trading is then resumed. Because the rights to the takings payment are no longer attached to the stock, the stock price should fall. The total takings payment would be equal to the decline in net capitalization. An advantage of this mechanism is that it relies on a firm's own shareholders to value its intellectual property. It seems likely to work effectively, however, only with relatively high value intellectual property, and there is some danger of noise associated with contemporaneous market events. A variation might be for the 
government to sell derivatives whose value is equal to the stock price decline observed over a set time interval and then to reimburse shareholders based on the expectation of the stock price decline. Of course, the government must guard against stock manipulation; it might help to randomize the exact time to be used for measurement of stock value.

\section{Flexible Ex Post Valuation and Hybrid Mechanisms}

A final approach is to allow for a relatively unconstrained assessment of social value to be made ex post. This ex post evaluation could be made judicially, for example in takings litigation as suggested by Guell and Fischbaum (1995), or through some form of administrative process. The case for flexible ex post valuation is that even if the government makes large ex post errors, these errors will have effects on ex ante investments only to the extent that they are systematic and can thus be anticipated. (Abramowicz 2003, pp. 218-224) Some systematic errors might exist, however. For example, Khan \& Sokoloff (2006, p. 25) demonstrated in an empirical study of prize awards that they often depended on factors such as elite education and geographical proximity. Perhaps decisionmakers also would favor consumer products relative to products that are inputs into other products. It is also possible that decisionmakers might adjust based on distributional considerations, favoring the poor. Arguably, such adjustments would help ameliorate inequality, though whether a reward system is an efficient mechanism for redistribution depends on the suboptimality of the existing distribution of wealth, as well as on the relative efficiency and plausibility of this mechanism in comparison to other vehicles for redistribution, such as taxation.

Duffy (2004a, p. 50) points out that if this worked "it could also be applied to other fields of natural monopoly or even to government procurement." That such an approach has not been applied even in those contexts may suggest that policymakers care about ex post fairness rather than just ex ante efficiency, or that policymakers believe that such a mechanism would not be effective. It is also possible that ex post valuation is less needed with natural monopoly or government procurement, because alternative approaches may be more viable than the patent system. Duffy also expresses a concern that flexible ex post valuation systems might invite rent seeking (pp. 50-51), citing the pioneer preference program of the Federal Communications Commission. This concern is reduced if assessments are to be made judicially rather than administratively.

The most significant advantage of ex post valuation relative to other valuation mechanisms is that decisionmakers can in principle take into account the full range of potentially relevant considerations. Kapczynski and Syed (2013, p. 1955) argue that a principle justification for reward systems is that existing intellectual property systems, such as patent law, may distort inventor incentives toward contributions where excludability is high and away from contributions 
where intellectual property owners will not be able to police violations. For example, the patent system may undervalue inventions whose value will be realized only with a long time delay; while the patent system appropriately causes potential inventors to discount anticipated revenues to the present, they will ignore anticipated use beyond the patent term. Market mechanisms also will not work as a mechanism for encouraging subpatentable inventions, i.e. small contributions that would not be worth the social cost of a patent but are nonetheless worth encouraging.

A market mechanism that simply attempts to replicate the private value that would be achieved by the patent system cannot overcome the limits of such a system. It is possible, however, to envision a hybrid system. For example, the government might hold a Kremer-like auction to provide a baseline for private valuation, but then use flexible ex post decisionmaking to determine the ultimate amount to be paid. This would allow the decisionmakers to focus specifically on the factors that would cause deviation between private and social value under a traditional intellectual property system. Similarly, if the Duffy taking system were employed, the government might be allowed to deviate up or down from the stock market valuation of a patent based on such considerations. Of course, an auction mechanism could also be combined with estimates based on sales. Kremer (1998, pp. 1160-61). A flexible ex post valuation could take into account a market valuation as well as a valuation based on sales.

\section{COMPARISON WITH TRADITIONAL INTELLECTUAL PROPERTY SYSTEMS AND OTHER ALTERNATIVES}

The above sketch of the history of prize and reward systems and description of design choices hint at the comparison between those systems and existing intellectual property institutions. The case for each approach focuses on the flaws of the other. A patent or reward system will seem attractive to those who look at the patent system and see deadweight loss, inefficient races, and high transactions costs. The patent system will seem preferable for those who believe that government would be ineffective in determining the appropriate size of awards. John Stuart Mill stated this case most famously and perhaps most persuasively:

[I]n general, an exclusive privilege, of temporary duration, is preferable, because it leaves nothing to anyone's discretion; because the reward conferred by it depends upon the invention's being found useful, and the greater the usefulness, the greater the reward; and because it is paid by the very persons to whom the service is rendered, the consumers of the commodity. So decisive, indeed, are these considerations, that if the system of patents were abandoned for that of rewards by the State, the best shape which these could assume would be that of a small temporary 
tax, imposed for the inventor's benefit, on all persons making use of the invention.

Mill (1858). The advocate of prizes might suggest the reverse deconstruction, recommending that the state alter the rewards of the market to account for its imprecision in rewarding social value, until ultimately there would be no remaining need to grant an exclusive property right and much savings from eliminating the patent apparatus. We will not adopt either of these polar opposite positions, but instead will consider the comparison along a number of dimensions, with attention to the many ways we have identified that prize and reward systems can be structured.

\section{A. Effects on Innovation}

Mill's quotation embraces the position that patent law is well calibrated to reward social value, because private returns will depend on success in the market. The views of consumers spending their own money should be preferred to the views of bureaucrats spending the money of others, for they may be more influenced by political considerations than economic ones. Spulber (2014), for example, highlights the Hayekian role that prices serve in a patent system and the difficulty that government will have in replicating the invisible hand. Partisans of both positions generally agree that the increase in consumer surplus created by an invention should count as an increase in social welfare, and so a system that provides inventors with some proportion of this increase is generally effective. On the other hand, one may argue that "the social worth of a good depends (at least in part) on values that are distinct from its utility to consumers." (Roin 2014, p. 1029) This motivates especially proposals regarding pharmaceuticals.

Advocates of prizes, however, emphasize that the imperfection in the correlation between social value created by an invention and the amount that can be appropriated by inventors. Appropriability, Kapczynski and Syed (2013) argue, depends largely on excludability. Many innovations - such as hospital checklists and the provision of information that drugs do not work - are not easily excludable, and so these will tend to be underproduced by the patent system. (p. 1908) Meanwhile, it may be difficult to monitor infringement with some inventions. (p. 1917) Some inventions, such as vaccines, may produce high positive externalities that the patent system does not value. Fisher and Syed (2012, p. 4) Others may produce a high percentage of their social value after the duration of any exclusive right, and will thus be underprovided. Finally, relative to social value, there will be relatively little incentive to produce discoveries and inventions that have high spillovers. Basic research exemplifies this. Patent law rejects patents on abstract ideas in part because of the difficulties of defining property rights on such ideas, but a prize or reward system can easily incentivize research that cannot be easily 
monetized through the patent system. Thus, a critical inquiry is to examine what proportion of useful research-not necessarily research being conducted, but research that might be incentivized either by patents or by prizes or rewards in a hypothetical optimal system - is not easily excludable. The higher this proportion, the stronger the case for a prize or reward system, though the possibility that other systems might be used to encourage such research (such as research grants, to be considered below) must also be considered.

The above are concerns about false negatives - that the patent system does not incentivize progress on much important research. But one can also argue for a reward system on the ground that patent systems have too many false positives. An examination of the literature on the effectiveness of patent offices in weeding out low-quality patents is well beyond this chapter's scope. One who perceives that many patents provide outsized rewards for minimal contributions may believe that a reward system may be more effective in preventing such distortions. A significant challenge in administering a patent system is rendering determinations of whether patents are nonobvious. Part of the problem may be that nonobviousness in patent law is a binary determination; in a reward system, by contrast, small rewards could be given for small degrees of nonobviousness and large rewards, for greater degrees of innovation. In principle, patent law can adjust scope based on the degree of innovativeness of an invention, but this may not be easy to accomplish administratively, and patent offices may not have strong incentives to push back against applicants who have made small innovations but claim broad scope. Even if these are problems of the patent system, however, the question becomes whether the best course is to abandon the patent system or to work to improve the patent system from within, for example by increasing the rigor of the nonobviousness standard, reforming patent scope, or changing patent litigation procedure.

In principle, a reward system can consider all forms of social welfare produced by an invention, including relatively nonexcludable forms. (A prize system, meanwhile, can also be used to reward any sort of creation, but the tendency of prize systems to specify one or more areas of interest in advance means that they will necessarily exclude consideration of many important discoveries outside their scope.) The heart of the objection to a reward system is that such a system may not effectively capture the benefits that the patent system misses and moreover may misestimate the benefits that the patent system captures. Calandrillo (1998, p. 340 n.155) notes that historically, prize systems have been rejected for largely this reason. Skepticism among economists stems about prizes stems largely from distrust of bureaucracies. Scherer (1973, p. 398) argues, "[A]ny bureaucratic council entrusted with the job is bound to make mistakes and perpetuate inequities." Similarly, Tirole (1988, p. 401) notes that "[i]nformation about demand is crucial for determining the size of the award, which, in turn, influences the research 
incentives." It may be difficult to estimate demand when a product is offered for free.

Virtually no empirical progress has been made in addressing these questions. Part of the problem, of course, is that we do not have reward systems. In principle, however, governmental officials or laboratory subjects might be tasked with estimating social value for experimental purpose. But such experiments might not be useful. It would be difficult to assess whether estimates of social value were correct, though it might be possible to determine whether subjects could accurately estimate the private value created by certain discoveries. Perhaps one could determine whether subjects were relatively consistent in their evaluations. But as long as rewards are given ex post, what matters are ex ante forecasts of evaluations, and even highly inconsistent decisionmakers might come close to approximating social value in expected value terms. Even if one could measure expectations of what average decisionmakers would decide, it may be impossible to know whether these expectations represent an improvement over expectations of what the market would reward.

Market mechanisms, like those described in Part IV.B, largely avoid the debate on whether patents or rewards are better calibrated to social welfare. Such a market mechanism seeks to buy out intellectual property at its private value, so it does not entail the risk that government officials will systematically misestimate invention value, nor does such a mechanism offer the potential of government officials steering inventive activity towards what is socially valuable. Thus, those mechanisms must be assessed largely based on their effectiveness at capturing private value and on benefits such as reduction in deadweight loss. Such a mechanism could be used to provide a baseline compensation level, with governmental officials permitted to deviate from that level only within some range. One might distrust the government to generate social value estimates of innovations being placed in the public domain but believe that governmental adjustments to the baseline of private value may improve the correlation between social value and private value.

A final point is that such correlations are not all that matters. A system for promoting intellectual property might reward contributions in exact proportion to their social value yet still fail if the size of the total contributions is too low or too high. An additional consideration is thus whether total incentives to innovate will be higher with rewards or with traditional intellectual property. Assuming private appropriation is likely to be less than social welfare on average with either system, the system that produces greater total rewards may be preferable. Reward system advocates highlight that rewards could be augmented to capture social value better. Kremer (1998, p. 1411) notes that patent buyouts may be at a multiple of private value and suggests that a markup between 2.5 and 3.33 may be socially desirable, and Shavell and van Ypersele (2001) point out that if government knows the 
demand curve, government can play social surplus and achieve a first-best outcome. Of course, what the government could do is not necessarily what the government will do. Kalil (2006, p. 11) notes that uncertainty of whether the government will pay reduces the effectiveness of a prize or reward. If government is thought likely to cheat or renege on open-ended commitments, then the optimal policy may be for the government to commit to a fixed pot. Abramowicz (2003). This eliminates the potential benefit of increasing total funds offered for innovation but also reduces the danger of underproviding for innovation, and it may be useful as a transitional mechanism, perhaps as a complement to the patent system.

\section{B. Effects on Redundant Innovation}

Both traditional systems of intellectual property and prize or reward systems may lead to inefficient redundant research. In a patent race, multiple competitors may attempt the same approaches, though sometimes they will attempt different strategies. Sometimes redundant efforts can be welfare-improving, especially where an invention has very high social value, but it is not a free lunch. Although patent races can lead to earlier invention, the anticipation of competition reduces potential participants' estimates of the expected payout from a race. In equilibrium, this can lead to later racing. (Duffy 2004b). Meanwhile, attempts to invent around an invention can also lead to inefficient duplication. Redundancy can also occur with a prize or reward system. If there is a single prize, the dynamics of racing will be quite similar to those in a patent system. With rewards, redundancy may still occur, whether competitors believe only the first to complete an achievement will receive a reward or whether competitors anticipate that the reward will be shared among all participants. Thus, patents, prizes, and rewards may all be inferior in this particular respect to a program of centralized government research, which can allocate funds to various research programs in a way that attempts to minimize or optimize redundancy.

As this analysis suggests, commentators generally agree that prizes and rewards do not necessarily solve the common pool problem. Calandrillo (1998, p. 353 ) notes that a "government-run reward system will not solve the race to be the first party to generate a given piece of information in order to obtain the reward for it," and Wright (1983) observes that an inefficiently high number of firms may respond to a prize incentive. In principle, however, operators of a reward system might seek to adjust rewards or prizes to combat redundancy, just as rewards in principle could be adjusted for any other purpose. Roin (2014, p. 1033). The problem is that it is not obvious exactly what adjustments should be made.

One possibility is to give considerably lower rewards where interest in a particular inventive path was stimulated by an exogenous shock, such as the emergence of a complementary invention. If Invention A enables Invention B, then the payment to the first to invent $B$ need not be the full social welfare value of $B$ 
over A. As noted above, social value is better measured against a baseline of what would have been invented absent an incentive, and an extension to this principle is that even if some incentive is necessary to encourage innovation, sometimes that incentive may be much lower than the full social value of the invention. Those operating the reward system might reduce the ex post award to the level that they believe would have produced optimal ex ante entry into the race. Of course, this introduces the risk of hindsight bias.

Another possibility is for the reward judges to provide strong incentives for very rapid release of information. If Inventor A performs Step X but does not report it, so Inventor B repeats Step X unnecessarily, then the reward judge might allocate the proportion of the reward attributable to Step X between Inventor A and Inventor B. If Inventor A reports Step X and is the first to complete Steps Y and Z necessary to produce the invention, then the case for sharing the reward with a later inventor who replicates A's steps is greatly reduced. Of course, a risk for Inventor A is that Inventor B will replicate and invent first. In this case, however, there is a strong case for giving Inventor A at least the credit for the portion of the reward attributable to Step X and perhaps more, if there was no reason to think that Inventor $\mathrm{B}$ would make a stronger contribution. A broader observation is that reward systems can provide incentives for taking intermediate steps on the way to a discovery, and more granular rewards can reduce redundancy. Reward systems may also choose to reward negative results. This presents a danger that inventors will choose paths that they believe are unlikely to be successful, but also encourages information sharing. With this determination as with others, it is difficult to identify principles to determine just how much credit should be given. A reward system will generally be more attractive if such micro-adjustments successfully adjust for distortions attributable to inefficient racing, and less attractive if the government is poorly situated to make the adjustments and may overcompensate.

\section{Effects on Commercialization}

Although the goal of the patent system is generally viewed as being encouraging research and invention, some commentators have emphasized that intellectual property may serve an important purpose in encouraging commercialization of invention. The patent prospect theory is widely associated with Kitch (1977, p. 277), who argues, "Only in the case of a patented product is a firm able to make the expenditures necessary to make the expenditures necessary to bring the advantages of the product to the attention of the customer without fear of competitive appropriation if the product proves successful." Kieff (2001) extends this insight to the literature on prizes and rewards, noting that if payments are given for inventive effort alone, but consumer demand is highly uncertain, then second-mover advantages may dominate first-mover advantages. Kieff emphasizes that patents serve a role in coordinating inventors and market players. 
A recent literature has assessed how intellectual property rights might be used to further the commercialization function. See Abramowicz \& Duffy (2008); Sichelman (2010). Hrdy (2015) emphasizes that in fact states frequently give awards to encourage commercialization, and these awards can be seen as analogous to a reward system. It is possible to imagine channeling such awards into a quasijudicial process. Entrepreneurs might be rewarded for bringing products to market where consumer demand is highly uncertain and second movers can be expected to enter the market. The question becomes whether reward judges can effectively determine the magnitude of such rewards and whether inaccurate rewards or insufficient attention to the commercialization function might lead to inferior performance relative to a patent system.

\section{Effects on Consumers}

\section{Deadweight Loss}

The most common justification for a prize or reward system alternative to the patent system is that a patent or reward system can reduce or eliminate the deadweight loss attributable to patents. The observation that monopolists will set output at a level that is inefficiently low from a social perspective is elementary. Wright (1983) was the first to develop this advantage of a prize or reward system in a rigorous analytical way. One question is how important deadweight loss is relative to other systemic imperfections. Arguably, static inefficiency is not as important as ensuring that the patent system generates as much economic growth as possible, though the dynamic benefits of intellectual property and prizes or rewards must be discounted to present value. Another question is how serious the problem of deadweight loss is. Leslie (2011, p. 813) notes that patentees may reduce deadweight loss by engaging in price discrimination, for example through tying arrangements if permitted by antitrust laws. Love and Hubbard (2007, pp. 1548-49) counter that price discrimination is difficult, arguing that many pharmaceuticals are sold only to the world's richest group of consumers, because pharmaceutical companies worry about arbitrage. Roin (2014, pp. 1024-25) agrees that the difficulty of stopping arbitrage, combined with the challenge of identifying who is unwilling to pay the monopoly price, may make price discrimination difficult. But prescription drug insurance produces a two-part pricing that may make the two-part pricing achieved by a prize or reward system unnecessary. (pp. 1048-49)

The deadweight losses associated with patents must in any event be compared against the deadweight losses associated with taxation. Wright's original model featured the simplifying assumption that "lump sum taxation is possible (or the marginal welfare cost of general revenue is negligible)." Wright (1983, p. 693) But the literature highlights that taxation causes economic distortions. Calandrillo 
(1998, p. 337); Abramowicz (2003, 200-01). Roin (2014, pp. 1026-27) notes the possibility that the loss from taxation might be even higher than the loss from patents. On the other hand, Calandrillo (1998, p. 314) suggests that taxes are less distortionary, because they apply to all goods or income rather than to just some subset of them. Hemel \& Ouellette (2013, p. 315) counter that "numerous deductions and exclusions ... upset this equivalence and increase the distortionary effect of income taxation."

Whatever the actual distortionary cost of taxation, commentators widely agree that there is political resistance to taxation. Hemel and Ouellette (p. 312) note that patents are unique in that they do not "necessarily impose a budgetary cost on the government (apart from the costs of administering the patent system)." If taxpayers prefer, or are more easily fooled by, the implicit taxation associated with intellectual property than the explicit taxation necessary for prizes or rewards, then prizes or rewards might be politically infeasible. This is not necessarily an argument on the merits against prize-or-reward systems, but a corollary may be that prize-orreward systems are likely to be underfunded because of their tax cost.

\section{Distribution and Labor Incentives}

A prize or reward system might benefit some consumers at the expense of others. Most obviously, if the social value is judged independent of consumers' willingness to pay, for example because health benefits to the poor and rich are counted alike rather than based on willingness to pay, then a prize or reward system would tend to encourage innovation that benefits both all people, rather than simply innovation that benefits the wealthy. Even if the reward is based on willingness to pay, there may be a progressive redistributive effect. If marginal cost is sufficiently low, the poor can consume a product placed in the public domain, regardless of whether their utility is taken into account in the reward calculation. Hemel and Ouellette (2013, p. 308) argue that any redistribution's normative desirability may depend on the type of good; that the patent system is subsidized by users may be more justifiable for luxury goods (say, improved boat hull designs) than for lifesaving pharmaceuticals. Of course, a normative analysis of any distributional consequences depends on one's views about the existing distribution. In principle, one might argue that distribution in favor of the poor would reduce incentives to work and thus harm efficiency, though the general assumption in the reward literature has been that progressive redistributions would be desirable.

Not all of a reward system's distributional effects can be classified entirely in terms of effects on the wealthy or the poor. The copyright system can be seen as a tax on readers, and the patent system as a tax on users of inventions. Reward or prize alternatives continues to provide benefits to those same groups, but the costs are imposed more broadly. Whether it is socially desirable, independent of efficiency effects, to redistribution from nonreaders to readers or from Luddites to 
those who enjoy the fruits of invention, is ultimately a normative question. Duffy (2004a, p. 44) cites Coase (1946, p. 176) in observing that rewards "would redistribute income in favor of those who consume declining average cost goods." Of course, if consumers are relatively homogeneous in their preference for declining average cost goods, this may be of little concern.

\section{E. Transactions Costs}

The costs of administering either a traditional intellectual property system or a system of rewards of prizes reduce social welfare. Calandrillo (1998, p. 341) argues that "the reward regime would save on the legal, private, and social enforcement costs involved in protecting property rights from theft, infringement, or copying by others." These costs are especially significant in the context of the patent system, encompassing both governmental and private costs associated with the prosecution and litigation of patents. Calandrillo argues that transaction costs for both copyright and patent are high in part because of complex doctrine. (pp. 331-34) Of course, a reward system must evaluate every invention or work and this entails some administrative costs as well. Though such evaluations might not track traditional doctrinal argument, they might involve complex economic analysis. Economists may not come cheaper than lawyers, who no doubt would find a way to become involved. Burrell and Kelly (2014, p. 887) argue that historically, the administrative costs of prizes may be higher than those of patents.

A full accounting must take into account not only the costs involved in dealings with government agencies and courts, but also the costs associated with private negotiation and evaluation. The patent system encourages private ordering, but private ordering depends on negotiation by private parties. Those parties may be able to find means of reducing their costs, for example by joining patent pools. A reward system may reduce the need for private negotiation, because intellectual property placed in the public domain can be used without charge. This may be especially important in the context of "patent thickets." (Heller and Eisenberg 1998) If a sufficient number of inventions are placed into the public domain, especially in a mandatory system, enough of the thicket may be cleared to facilitate follow-on invention.

Market-based reward systems must be evaluated separately, because they combine elements of the other approaches. Because a market-based reward system requires that traditional intellectual property institutions still exist and that patents still be obtained, the transactions costs associated with the patent office remain. Litigation, however, may be greatly reduced with respect to the patents randomized to the public domain. But the market mechanism itself involves transactions costs, as auction theory predicts that the private parties participating in a Kremer auction will lower their bids to account for their research costs. Such transactions costs may be reduced with the Duffy market valuation approach, because each individual 
shareholder has only a limited incentive to engage in research. But the downside of that may be less accurate market valuation. As long as shareholders value patents correctly on average, however, this should not adversely affect ex ante investments in research, except to the extent that it makes them somewhat riskier.

\section{F. Rent-Seeking Costs}

Perhaps one of the great achievements of the patent system is that it has greatly reduced rent-seeking by inventors seeking special treatment for their individual inventions. In principle, Congress can grant patent term extensions on an invention-by-invention basis, but because the patent system exists and imposes uniform rules governing patent term, this rarely occurs. A concern with the creation of a prize or reward system is that owners of rights to inventions might lobby for those inventions to receive high rewards. Hemel and Ouellette (2013, p. 327) worry that rewards might lead to "politicization, rent-seeking, and mismanagement," pointing out that "the social rate of return on R\&D funded through government grants has been estimated to be lower than on private R\&D." Duffy (2004a) also points out that consumers might lobby for the government to choose products that they use to be placed in the public domain. The investments in such lobbying would be social losses, and they might distort decisionmaking. In a judicialized reward process, however, it may be possible to maintain decisionmaker independence. In that case, rent-seeking could be accomplished only by persuading the reward judges of the worth of one's invention. Inventors, however, may have incentives to mislead judges about the value of their contributions, for example by suppressing negative studies about their inventions' effectiveness.

\section{G. Other Policy Options}

\section{Grants}

Most of this chapter has compared traditional intellectual property systems to a range of possible prize or reward systems. But these are, of course, not the only means by which the government can encourage innovation. An approach closely related to that of rewards is grants. Grant decisions are made by centralized agencies ex ante based on research proposals. Adler (2011) argues that prize or reward systems may be preferable, because the centralized grant decisions limit "the range of promising ventures that may receive funding." Hanson (1998) argues that grants have become more important than prizes because they tend to concentrate power in the hands of scientific rather than political leaders. While legislatures would like to maintain such power in their own hands, the power to administer prizes is more likely executive than legislative, and legislatures prefer to grant power to scientific leaders than to the executive. The general normative 
case for grants, particularly for basic research, is that "a large share of the most valuable uses of basic research will take highly abstract, intangible forms, rendering the output of such research highly nonexcludable.” Kapczynski \& Syed (2013, p. 1951).

\section{Governmental Purchases and Tax Credits}

Above, we noted that the government might create something akin to a prize system by giving coupons to low-income consumers. There may also be other ways by which the government can help consumers obtain patented products in a way that reduces deadweight loss, yet possibly without the need to evaluate the contributions of individual inventions. For example, the U.S. government subsidizes health insurance through its tax code. Roin (2014, p. 1051) argues that this may be administratively much simpler than giving coupons to individual consumers. Health insurance creates a two-part pricing scheme for pharmaceuticals. Consumers pay a fixed amount for health insurance and then a copayment for individual prescriptions. This copayment may be relatively close to marginal cost. Roin also argues that the government might combine subsidies for health insurance with price controls to ensure that the consumer price ends up relatively close to marginal cost. Many national health systems help to drive prices for consumers to levels near marginal cost without creating a formal prize system. The effect, he argues, is to create the benefits of a patent buyout scheme while retaining the system of intellectual property and arguably reducing the informational demands on the government. It may not be easy to apply the same logic outside the health insurance context, though in principle a combination of private ordering and governmental subsidies could reduce consumer costs for other goods. Consumers often buy goods (such as cable television subscriptions) with a high fixed and low marginal price component, and government policy could further encourage this.

We have, of course, only scratched the surface of the ways in which the government can create innovation through its own purchases. Carroll (2009, p. 1369-70) offers an expanded taxonomy of means by which the government can encourage innovation, noting the possibility of "direct provision of creators or innovators employed by the government." Kalil (2006, p. 7) argues that a benefit of prize-and-reward systems it that they avoid the complexities associated with procurement regulations and can thus attract teams who otherwise would not be positioned to do business with the government. Brennan et al. (2012, p. 27) offer some guidance on when procurement may be appropriate. While grants will be useful when the government wishes to reduce the risks of inventors but does not know the best approach to take, procurement will work better for a known objective and solution. Prizes may reduce risk somewhat and may be especially appropriate 
where a specific objective is known but the means to obtain that objective is unknown.

Hemel and Ouellette (2013) argue that tax credits also have potential advantages as means of funding innovation. Tax credits require less direct governmental involvement and supervision than any of the other methods of encouraging innovation. Tax credits, they argue "may be optimal where potential innovators have private information about project prospects and limited access to outside capital." (p. 303) Tax credits can be structured as deductions or as refundable, which provides stronger incentives for startup companies. Tax credits can either be administered at a national level or at a state level. Hrdy (2013) argues that in part because a variety of doctrines limit the ability of states to create patent policies, states have focused largely on providing tax credits as a mechanism for encouraging innovation. As Hrdy's argument suggests, a significant drawback of tax credits relative to rewards is that they provide the government relatively little ability to adjust for ways in which the patent system may not align private and social incentives.

\section{CONCLUSION}

The arguments for and against prize and reward systems are many and all depend on empirical considerations that, without experimentation, are difficult to assess with confidence. On one hand, there are strong theoretical reasons that an ideal prize or reward system could dominate an ideal patent system because of the reduction of deadweight loss and because rewards can be adjusted to encourage or discourage any desired or disfavored activity. But no system is ideal. As Kremer (1998, pp. 1162-63) points out, new mechanisms will have "risks and shortcomings," but "existing mechanisms of encouraging innovation have serious flaws" as well. Thus, a full comparison depends on considerations such as which system can better encourage commercialization, which system entails larger transactions costs, and which system can best reduce inefficient rent-seeking. Perhaps limited governmental experimentation with prize or reward systems can reduce some of the uncertainty about these costs, but individual governments may have only limited incentives to experiment, particularly given their obligations to maintain intellectual property rights under existing trade laws. Perhaps the increased scholarly interest in prize and reward systems anticipates increased governmental interest in these systems. Levmore (2013) argues that the increasing importance of ideas in the modern economy and the difficulty of creating property rights in ideas and the drawbacks in enforcing such property rights mean that prizes and rewards will take on increasing importance in the future. Pharmaceuticals may be the most likely target for experimentation (pp. 156-157), given concerns about deadweight loss, scholarly and policy interest in that area, and the already large spending and research by governments on health. 